\title{
Persistent Blood Flow inside the Woven EndoBridge Device More Than 6 Months after Intracranial Aneurysm Treatment: Frequency, Mechanisms, and Management-A Retrospective Single-Center Study
}

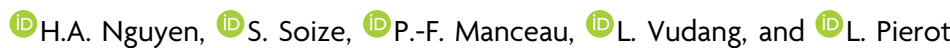

\begin{abstract}
BACKGROUND AND PURPOSE: Due to its high safety and great efficacy, flow disruption with the Woven EndoBridge (WEB) device is increasingly used to treat intracranial aneurysms. We recently identified patients with intracranial aneurysm treated with the WEB who presented with residual blood flow inside the device ("contrast-in-WEB" phenomenon) more than 6 months posttreatment. This series reports the frequency and underlying mechanisms and discusses management of this phenomenon.
\end{abstract}

MATERIALS AND METHODS: All patients presenting with the contrast-in-WEB phenomenon in the prospectively collected data base of patients with aneurysm treated with the WEB were retrospectively collected and analyzed.

RESULTS: From June 2011 to February 2019, one hundred twenty-seven patients with 133 aneurysms were treated with the WEB and had DSA follow-up at 6 months or later. Eight patients (6.3\%) presented with the phenomenon. All aneurysms were wideneck bifurcation aneurysms, including 7 unruptured and 1 ruptured aneurysm located at the MCA (5 aneurysms), anterior communicating artery ( 2 aneurysms), and basilar artery (1 aneurysm). All except 1 patient received dual-antiplatelet therapy preprocedure. All except 1 patient received dual-antiplatelet therapy postoperatively for at least 1 month. The most likely mechanism of the phenomenon is the absence of intradevice thrombosis related to perioperative dual-antiplatelet medication. The phenomenon is also likely associated with a low risk of bleeding except when there is residual blood flow against the aneurysm wall or in the dome.

CONCLUSIONS: Contrast-in-WEB is a relatively rare phenomenon possibly induced by dual-antiplatelet therapy continued postWEB procedure. In most cases, no additional treatment is required.

ABBREVIATIONS: DAPT $=$ dual-antiplatelet therapy; DL $=$ dual-layer; $\mathrm{SL}=$ single-layer

$\mathbf{F}$ low disruption with the Woven EndoBridge (WEB; Sequent Medical, Aliso Viejo, California) system is a new approach for treatment of wide-neck bifurcation aneurysms. ${ }^{1}$ The system disrupts blood flow entering the aneurysm by inducing intra-aneurysmal (and intradevice) thrombosis that usually occurs hours following the procedure. Because the WEB is an intrasaccular device, dual-antiplatelet treatment is not necessary before or after the procedure, and its use can be extended to ruptured aneurysms. ${ }^{2-6}$ Since its first use in humans in 2011, the safety and efficacy of the WEB has been evaluated in several prospective, multicenter, Good Clinical Practice

Received February 6, 2020; accepted after revision April 14.

From the Department of Radiology (H.A.N., L.V.), Bach Mai Hospital, Hanoi, Vietnam; and Department of Neuroradiology (H.A.N., S.S., P.-F.M., L.P.), Hôpital Maison-Blanche, Reims, France.

Please address correspondence to Laurent Pierot, MD, PhD, Department of Neuroradiology, Hôpital Maison-Blanche, 45 rue Cognacq-Jay, 51092 Reims cedex, France; e-mail: Ipierot@gmail.com

http://dx.doi.org/10.3174/ajnr.A6593 studies. $^{2-5,7-14}$ The level of procedural safety has been extremely high with no mortality and a morbidity rate of between $0.7 \%$ and $3.0 \%$ at 1 month. ${ }^{2,3}$ Adequate occlusion (complete occlusion and residual neck) according to the WEB occlusion scale was observed between $79.1 \%$ and $84.6 \%$ after 1-year follow-up. ${ }^{2-4}$ Long-term efficacy is still being evaluated after the so-called "compression" phenomenon, more a "retraction" process related to thrombosis into the device as part of the healing process, was reported. ${ }^{15,16} \mathrm{~A}$ recent publication about the global population of 3 European WEB studies confirms robust stability of the treatment at 2-year follow-up. ${ }^{17}$

During the follow-up of our large series of patients treated with the WEB since 2011, we observed the presence of residual flow inside the device $>6$ months after treatment ("contrast-in-WEB phenomenon"). Because this phenomenon was not previously analyzed, we conducted a retrospective study to investigate its incidence and underlying mechanisms and to propose optimal patient management. 


\section{MATERIALS AND METHODS}

This retrospective, single-center study was conducted between June 2011 and February 2019. According to the retrospective design of the study, institutional review board or ethics committee approval was not required. Patients gave oral informed consent for their data use.

\section{Study Design}

Patients were included if

- They had an intracranial aneurysm treated with the WEB device with or without adjunctive materials.

- They were followed-up with DSA at 6 months or later.

- There was residual flow inside the device at least 6 months posttreatment.

Patients were excluded if they did not have at least a 6-month DSA follow-up or if they refused to participate in the study.

\section{WEB Embolization Technique}

All patients had coagulation evaluation before the WEB procedure, which included prothrombin time-international normalized ratio, activated clotting time, fibrinogen, and platelet count.

The procedure was performed on a biplane angiographic system (AlluraClarity; Philips Healthcare) with patients under general anesthesia. Patients with unruptured aneurysms received dual-antiplatelet therapy a few days before the procedure, using 2 different protocols, which were implemented successively using aspirin, $75 \mathrm{mg} /$ day, plus clopidogrel, $75 \mathrm{mg} /$ day for 5 days, or aspirin, $75 \mathrm{mg}$ /day, plus ticagrelor, $90 \mathrm{mg}$, twice daily for 2 days. We did not perform antiplatelet testing. All patients (with ruptured and unruptured aneurysms) received a loading dose of IV heparin (Panpharma; Luitré, France), 50 U/kg, after femoral puncture followed by IV infusion of $1000 \mathrm{U} / \mathrm{h}$ during the procedure. Postoperatively, all patients received aspirin, $75 \mathrm{mg} /$ day, for at least 5 weeks; with stent placement or WEB protrusion, clopidogrel or ticagrelor (same doses) was also given with variable durations.

Triaxial access (long introducer sheath, distal access catheter, and microcatheter) was used routinely for the placement of the WEB device. The microcatheter was a VIA (Sequent Medical).

Using measurements obtained on 3D-DSA images, we performed WEB device sizing. The size of aneurysm including width, height, and neck was measured in 2 orthogonal planes. Then, following oversizing recommendations $(1 \mathrm{~mm}$ added to the average width and a decrease of $1 \mathrm{~mm}$ in height), we chose the WEB.

\section{Imaging Follow-Up}

Anatomic follow-up was performed by 3T MR imaging and DSA according to a previously published protocol. ${ }^{18}$ In the most recent follow-up (since September 2018), VasoCT (Philips Healthcare) was performed using a diluted iodine contrast agent with $15 \%$ iodixanol (Visipaque 270; GE Healthcare) and an $85 \%$ saline solution. The total volume used was $90 \mathrm{~mL}$ at an injection rate of $3 \mathrm{~mL} / \mathrm{s}$.

\section{Data Collection}

A prospective data base of all patients with aneurysms treated with the WEB is maintained. The files and follow-up images of all patients were reviewed by a physician not involved in the WEB procedures to identify all patients with persistent contrast inside the WEB at 6 months' follow-up or later. Aneurysm characteristics and treatment modalities were collected in the electronic medical records system and retrospectively reviewed.

To determine the role of dual-antiplatelet therapy (DAPT) in the occurrence of the contrast-in-WEB phenomenon, we analyzed the files of the 119 patients treated during the recruitment period who did not present with the phenomenon. The reasons for placing the patients under DAPT after the procedure were collected.

\section{Data Analysis}

An interventional neuroradiologist with 4 years' experience independently analyzed the images. The following elements were analyzed on 2D-DSA and VasoCT: Opacification of the WEB was classified as complete when the full device was opacified with contrast and partial when it was partially opacified with contrast (Fig 1). Additionally, the presence of contrast in the aneurysm neck or in the aneurysm sac (at the level of the dome) was evaluated.

In addition to evaluating residual flow in the WEB device and the aneurysm, we evaluated potential modification of the WEB shape by observation and direct measurement of the distance between both proximal and distal markers in the same DSA projection using 2D-DSA nonsubtracted images.

\section{RESULTS}

From June 2011 to February 2019, one hundred twenty-seven patients with 133 aneurysms (124 unruptured and 9 ruptured) were treated with the WEB device (20 patients/21 aneurysms with the WEB-dual-layer [DL], 107 patients/112 aneurysms with the WEB-single layer [SL] or WEB-single-layer spherical [SLS]) and had DSA follow-up at 6 months or later. Eight patients (6.3\%) met the inclusion/exclusion criteria of the study for the contrast-in-WEB phenomenon.

\section{Aneurysm Characteristics}

The study group comprised 8 aneurysms presenting with residual blood flow in the device at 6 months' follow-up or later. Seven aneurysms were unruptured, and one was ruptured. All aneurysms were wide-neck bifurcation aneurysms located at the MCA (5 aneurysms), anterior communicating artery (2 aneurysms), and basilar artery (1 aneurysm). Regular shape was dominant (6 aneurysms). Aneurysm characteristics are shown in Table 1.

\section{Antiplatelet Treatment}

Preoperative coagulation evaluation findings were normal in all patients.

Three of 8 patients with the contrast-in-WEB phenomenon received long-term antiplatelet therapy before treatment of cerebral aneurysms due to their comorbidities, including mono antiplatelet therapy in 1 (patient 5) and DAPT in 2 (patients 4 and 6). Before the procedure, 1 patient received DAPT with oral aspirin, $75 \mathrm{mg}$, and clopidogrel, $75 \mathrm{mg}$, daily for 5 days (patient 1) and 6 patients received DAPT with aspirin, $75 \mathrm{mg}$, and 


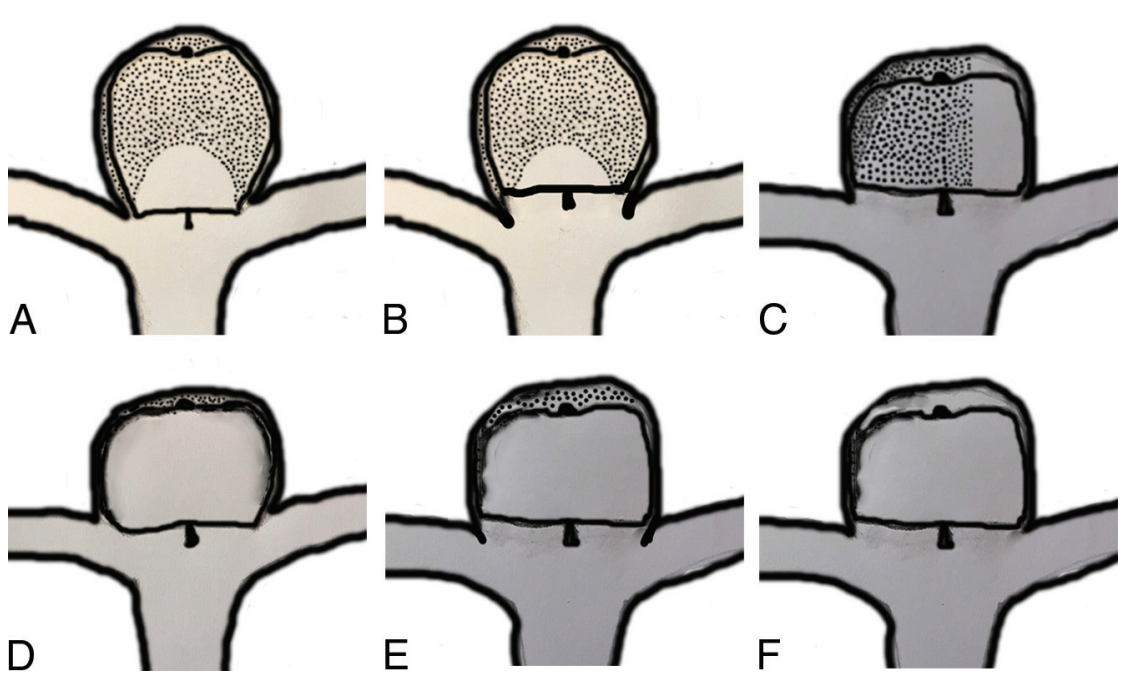

FIG 1. Different types of contrast-in-WEB phenomenon. Areas with black spots are thrombosed. $A$, Partial opacification of the WEB without opacification of the neck or aneurysm. B, Partial opacification of the WEB and opacification of the neck (neck remnant). C, Partial opacification of the WEB and aneurysm dome (aneurysm remnant). D, Complete opacification of the WEB without opacification of the neck or aneurysm. E, Complete opacification of the WEB and opacification of the neck (neck remnant). F, Complete opacification of the WEB and opacification of the aneurysm (aneurysm remnant).

Table 1: Aneurysm characteristics and WEB deployed

\begin{tabular}{llcccccc}
\hline No. & Location & $\begin{array}{c}\text { Wac } \\
\text { Width }\end{array}$ & $\begin{array}{c}\text { Sac } \\
\text { Height } \\
(\mathbf{m m})\end{array}$ & $\begin{array}{c}\text { Neck } \\
\text { Width } \\
(\mathbf{m m})\end{array}$ & $\begin{array}{c}\text { Dome-to- } \\
\text { Neck Ratio }\end{array}$ & $\begin{array}{c}\text { Ruptured } \\
\text { Status }^{\text {a }}\end{array}$ & $\begin{array}{c}\text { WEB } \\
\text { Deployed }\end{array}$ \\
\hline 1 & AcomA & 6.0 & 4.7 & 4.5 & 1.3 & 0 & SL 7-3 \\
2 & BA & 3.4 & 5.0 & 3.2 & 1.1 & 0 & SL 5-3 \\
3 & MCA & 7.2 & 5.9 & 5.5 & 1.3 & 0 & SL 8-3 \\
4 & MCA & 6.7 & 4.0 & 6.0 & 1.1 & 0 & SL 7-3 \\
5 & MCA & 5.3 & 3.9 & 4.4 & 1.2 & 0 & SL 6-3 \\
6 & MCA & 3.2 & 4.5 & 3.3 & 1.0 & 0 & SL 4.5-3 \\
7 & MCA & 5.2 & 5.0 & 4.4 & 1.2 & 0 & SL 7-3 \\
8 & AcomA & 3.7 & 4.1 & 3.0 & 1.2 & 1 & SL 4.5-2 \\
\hline
\end{tabular}

Note:-AcomA indicates anterior communicating artery; BA, basilar artery.

${ }^{a} 0$, Unruptured; 1, ruptured.

ticagrelor, $90 \mathrm{mg}$, twice daily for 2 days (patients 2 to 7). After the intervention, 6 of the 7 patients with unruptured aneurysm were treated with DAPT for at least 2 months: One because the patient (patient 3) was treated with the WEB and stent (DAPT for 3 months), 1 because the patient (patient 7) had a WEB protrusion (DAPT for 2 months), and the remaining 4 patients (patients 1, 4, 5, and 6) due to comorbidities, with permanent DAPT in 2 (patients 4 and 6), DAPT for 3 months in 1 (patient 5 ), and DAPT for 2 years in 1 (patient1 ). The patient with a ruptured aneurysm (patient 8) was treated with DAPT for 1 month followed by mono antiplatelet therapy due to the WEB protrusion.

Among the 119 patients who did not present with the contrast-in-WEB phenomenon, 36 (30.3\%) received DAPT after the procedure. In 20 patients, this treatment was given due to placement of a stent ( 15 patients) or a flow diverter ( 5 patients) during the procedure. Three patients were treated permanently with DAPT related to cardiac disease or previous stroke, and 13 patients, due to WEB protrusion.

\section{Procedure}

The WEB alone was successfully deployed and detached in 7 aneurysms. One MCA aneurysm was treated with the WEB and a rescue stent because of important WEB protrusion (patient 3). All WEBs used were WEB-SL, including 27 devices in 2 aneurysms, 21 devices in 1, and 17 devices in 5 . In all except 1 patient (patient 4), the WEB was oversized in width according to current recommendations. The size of the WEB is reported in Table 1.

\section{Complications and Initial Results}

No intraoperative complications occurred in any patient.

Immediate postoperative DSA, including 2D-DSA in all patients and VasoCT in 3 patients, showed residual flow inside the WEB in 3 patients and inside as well as around the WEB in 5 patients.

\section{Clinical and Imaging Follow-Up}

The mean follow-up time was $18.75 \pm$ 13.4 months (range, 6-48 months). All patients remained clinically normal during the follow-up period (mRS 0). No bleeding or rebleeding was observed during this period.

DSA follow-up was performed at 6 months in all except 1 patient, at 1 year in all except 1 patient who was pregnant, at 2 years in 2 patients, and at 4 years in 1 patient.

All aneurysms and patients underwent at least 1 VasoCT during the follow-up, showing partial WEB opacification without neck or aneurysm opacification (Fig 2) in 3 patients (patients 2, 5, and 6), complete WEB opacification without neck or aneurysm opacification (Fig 3 ) in 3 patients (patients 1, 7, and 8), partial WEB opacification and neck opacification (Fig 4) in 1 patient (patient 3), and complete WEB opacification and dome opacification (Fig 5) in 1 patient (patient 4). This last patient was treated with an inappropriately oversized (mean aneurysm width, $6.7 \mathrm{~mm}$, and the implanted device was a WEB $17 \mathrm{SL} 7 \times 3 \mathrm{~mm}$ ) WEB device.

Measurement of the WEB postoperatively and during followup did not reveal height modification. Among 7 patients followed up after 6 months, the residual opacified part was completely thrombosed at 1 year in 1 patient (patient 5 , in this patient DAPT was discontinued after 3 months), had slightly decreased after 4 years in 1 patient (patient 1), and was unchanged after 1 year in 3 patients (patients 4, 6, and 8) and after 2 years in 2 patients (patients 2 and 3). The height modification of the WEB is shown in Table 2. 

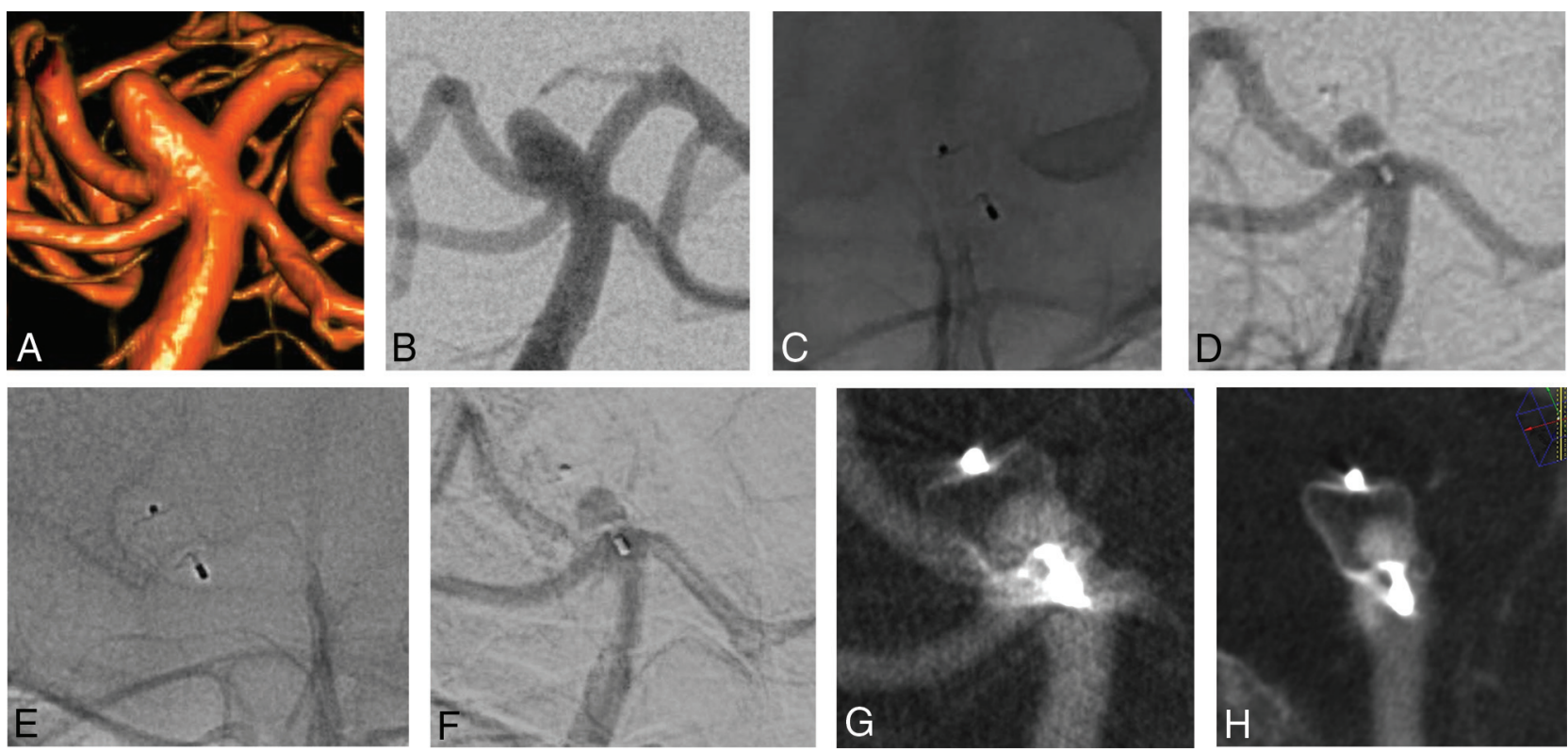

FIG 2. 3D $(A)$ and 2D (B) DSA show a basilar artery aneurysm. Nonsubtraction $(C)$ and subtraction $(D)$ images of the first DSA follow-up after lyear show partial filling of the WEB with contrast. A similar finding is observed at 2 years $(E$ and $F)$. VasoCT in 2 different views $(G$ and $H)$ confirms a partial opacification of the WEB and no opacification of the aneurysm.
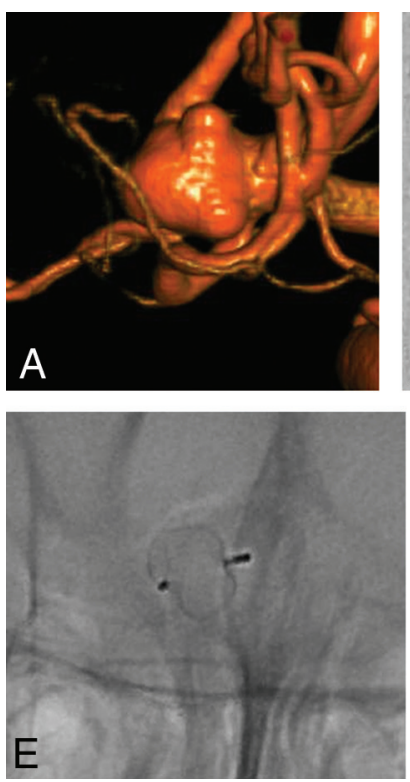
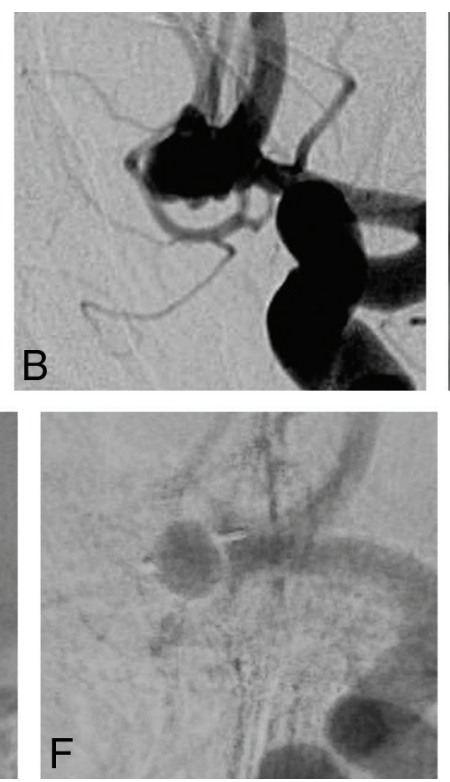
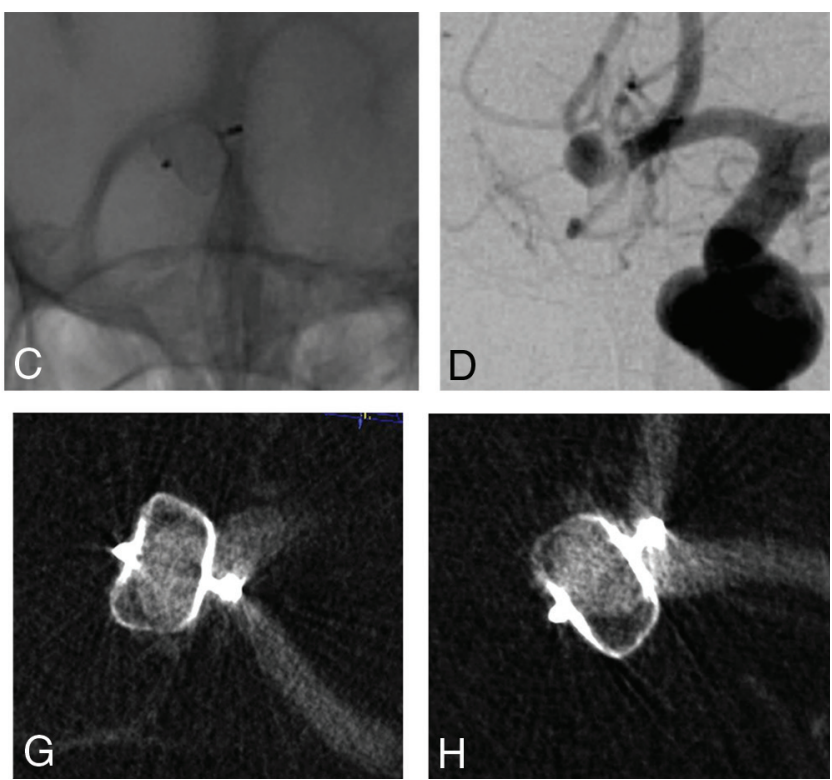

FIG 3. $3 D(A)$ and $2 D(B) D S A$ show an anterior communicating artery aneurysm. Nonsubtraction $(C)$ and subtraction $(D)$ images of the first DSA follow-up after 6 months and of the latest DSA follow-up after 4 years ( $E$ and $F$ ) show complete filling of the WEB with contrast. VasoCT in 2 different views $(G$ and $H$ ) shows opacification of the WEB and no opacification of the aneurysm.

\section{Retreatment}

The patient who had residual flow in the aneurysm dome (patient 4) was retreated by clipping 15 months after the initial WEB procedure.

\section{DISCUSSION}

This series describes a phenomenon, contrast-in-WEB, observed after WEB aneurysm treatment, which is persistent blood flow inside the WEB device $\geq 6$ months post-WEB treatment. The phenomenon is illustrated by a persistent opacification inside the WEB device on DSA and is well-visualized on VasoCT. This persistent WEB opacification can be partial or complete and is sometimes associated with residual opacification of the neck or dome. This phenomenon has been very rarely reported in the literature ( 2 cases, one of them being included in the present series) and was relatively rare $(6.3 \%)$ in our single-center series. ${ }^{19,20}$ It likely also exists after aneurysm coiling as shown by some experimental studies but is difficult to depict due to coil artifacts. ${ }^{21}$ The phenomenon was observed in both ruptured and unruptured aneurysms exclusively with the WEB- 
Table 2: WEB shape modification

\begin{tabular}{lcccccc}
\hline No. & $\begin{array}{c}\text { Height } \\
\text { Postoperat- } \\
\text { ion (mm) }\end{array}$ & $\begin{array}{c}\text { Height } \\
\text { after 6 } \\
\text { Months (mm) }\end{array}$ & $\begin{array}{c}\text { Height } \\
\text { after 1 } \\
\text { Year (mm) }\end{array}$ & $\begin{array}{c}\text { Height } \\
\text { after 2 } \\
\text { Years (mm) }\end{array}$ & $\begin{array}{c}\text { Height } \\
\text { after 3 } \\
\text { Years (mm) }\end{array}$ & $\begin{array}{c}\text { Height } \\
\text { after 4 } \\
\text { Years (mm) }\end{array}$ \\
\hline 1 & 6.2 & 5.8 & 5.8 & 5.9 & 5.6 & 5.8 \\
2 & 3.6 & - & 3.4 & 3.6 & - & - \\
3 & 7.8 & 7.9 & 7.6 & 7.7 & - & - \\
4 & 5.5 & 5.9 & 5.1 & - & - & - \\
5 & 5.4 & 6.0 & 5.8 & - & - & - \\
6 & 4.1 & 4.2 & 4.1 & - & - & - \\
7 & 6.0 & 6.0 & - & - & - & - \\
8 & 3.7 & 3.7 & 3.8 & - & - & - \\
\hline
\end{tabular}

Note:-- indicates no imaging was performed at this date.

SL and was persistent in all but 1 patient (the longest follow-up being 4 years). Thus, further thrombosis inside the WEB is rarely observed during follow-up, when the phenomenon is detected at 6 months.

\section{Mechanisms}

The first important point is that the persistence of blood flow inside the device shows that thrombosis inside the device did not occur; instead, blood flow is related to coagulation factors related to the patient or the treatment the patient received or mechanical factors related to the device.

Findings of the coagulation evaluation (prothrombin timeinternational normalized ratio, activated clotting time, fibrinogen levels, and platelet count) systematically performed before all endovascular treatment procedures of aneurysms were normal in all patients. All patients received heparin treatment during the procedure, which was stopped within 24 hours postprocedure; therefore, it seems unlikely that heparin plays a role in the phenomenon. In all except 1 case, patients received DAPT preprocedure. Finally, all except 1 patient received DAPT postoperatively for at least 1 month. DAPT is used preoperatively because the WEB treatment is dedicated to wide-neck bifurcation aneurysm treatment associated with a higher risk of thromboembolic complications than narrow-neck aneurysms during endovascular treatment. $^{22}$ Moreover, in case of WEB treatment failure, an alternative endovascular treatment option is stent-assisted coiling using DAPT. DAPT is used postoperatively if a stent is placed in combination with the WEB or in cases in which there is WEB protrusion with reduction of the caliber of 1 bifurcation branch. DAPT likely prevents initiation of the intradevice thrombosis process, which will not occur even after a change to mono antiplatelet therapy or even after stopping all antiplatelet medications.

Thirty-six patients treated with the WEB and receiving DAPT after the procedure did not present with the contrast-in-WEB phenomenon. Among them, an additional device (stent or flow diverter) was placed in front of the aneurysm neck in 20 patients and probably explained why these patients did not present with the phenomenon. However, it seems that the placement of a stent did not completely prevent the phenomenon because 1 patient with it was treated with the WEB and a stent. Finally, 13 patients received DAPT because of WEB protrusion, and the fact that they did not present with the phenomenon shows that other individual factors play a role.

All patients were treated with the WEB-SL; this phenomenon was not observed with dual-layer devices (WEB-DL). Because a limited number of patients $(20 / 127$ or $15.7 \%)$ were treated with the WEB-DL in our global series, it is not possible to confirm whether this phenomenon also occurs with this device. According to their design, the dual-layer devices have a double layer at the proximal surface level, while single-layer devices have 1 layer. The new braiding used for singlelayer devices is different from that used for dual-layer devices and includes a high wire density; both devices offer equivalent anatomic results in longterm follow-up. ${ }^{17}$

Another potential factor is mechanical and related to oversizing in the width of the WEB device. Oversizing the WEB width is associated with lateral compression and device deformation, which can potentially modify the porosity of the device, especially at its periphery. However, the expectation is that the more oversized the device is, the lower its porosity will be, which has been confirmed by some laboratory tests (unpublished data). Even so, the only case in which the device was not oversized (patient 4) was associated with a less favorable anatomic situation (contrast in the WEB and in the aneurysm dome), which required retreatment.

Finally, in 1 patient (patient 3), a rescue stent was placed in front of the aneurysm neck after the WEB deployment. In this patient, the stent potentially played a role in the contrast-inWEB phenomenon occurrence and the neck opacification that was observed in this patient by displacing the WEB too much.

At the moment, on the basis of our series, we hypothesize that the contrast-in-WEB phenomenon likely occurs due to perioperative antiplatelet medication (namely postoperative DAPT). Additionally, our series reveals that the worst cases (association of neck or aneurysm opacification) seem to be associated with WEB undersizing or additional stent placement.

\section{Management of Contrast-in-WEB Phenomenon}

According to the hypothesized mechanism of the phenomenon, its prevention should focus on fine-tuning the perioperative antiplatelet medication, which suggests avoiding postoperative DAPT; this has 2 consequences: 1) DAPT can be given preoperatively but has to be stopped postoperatively, and 2) patients under chronic DAPT for other health problems should probably not be treated with the WEB. As discussed, the WEB device still needs to be adequately oversized in width, given that it does not seem to play a role in the contrast-in-WEB phenomenon. ${ }^{16}$

The next question is what to do in cases of existing contrast-inWEB phenomenon? Briefly, 3 situations can be encountered. First, the contrast is only visible inside the WEB device and not around it (Figs 2 and 3). In this case, because there is no blood flow in contact with the aneurysm wall, the risk of rebleeding is probably very low or nonexistent and no additional treatment is required other than regular follow-up. Second, when contrast is seen inside the WEB and at the neck (Fig 4), the risk of bleeding is probably low, as in the case of any neck remnant. ${ }^{23}$ In this case, regular follow-up is required to identify any increase in the size of the contrast 

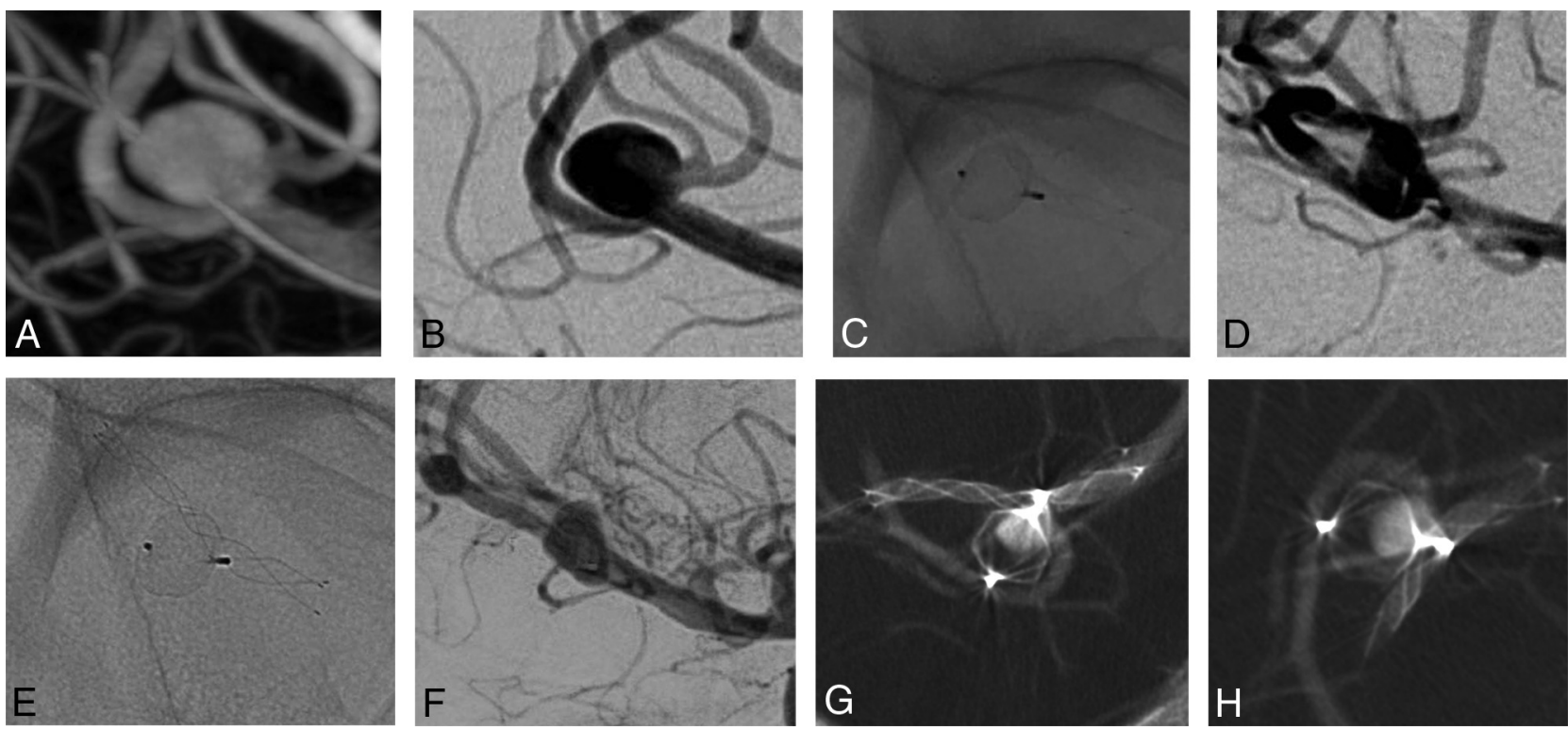

FIG 4. $3 D(A)$ and $2 D(B) D S A$ show an MCA aneurysm. Nonsubtraction $(C)$ and subtraction $(D)$ images of the first DSA follow-up after 6 months and of the latest DSA follow-up after 2 years $(E$ and $F)$ show partial opacification of the WEB and the aneurysm sac, confirmed by VasoCT in 2 different views $(G$ and $H)$.
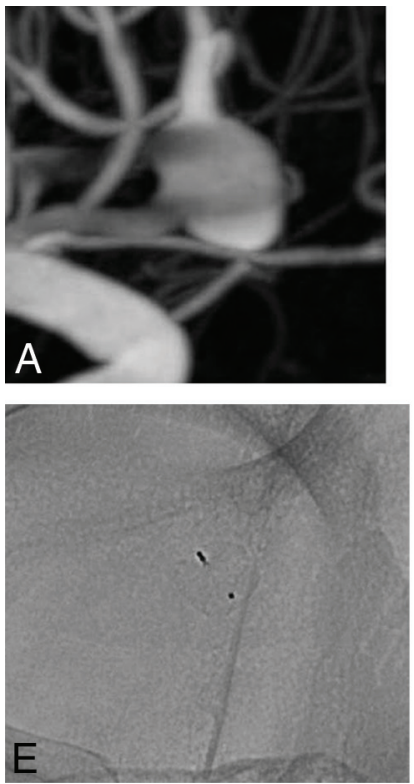
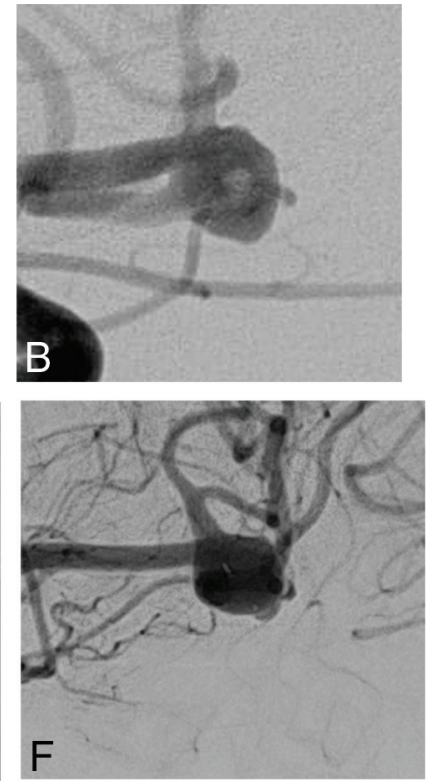
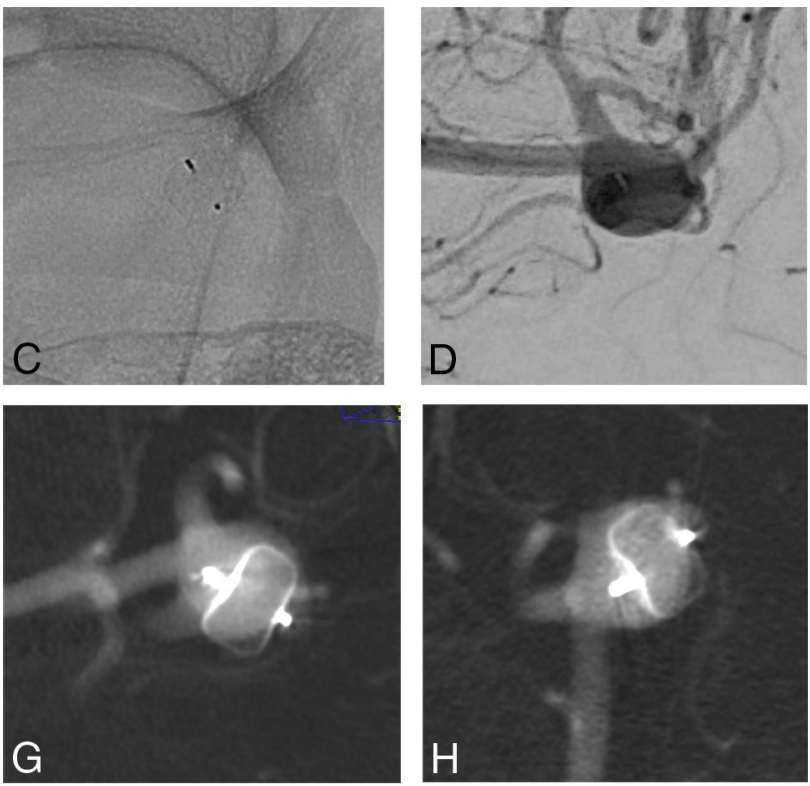

FIG 5. 3D $(A)$ and 2D $(B)$ DSA show an MCA aneurysm. Nonsubtraction $(C)$ and subtraction $(D)$ images of the first DSA follow-up after 6 months and of the latest DSA follow-up after 1year ( $E$ and $F$ ) show complete opacification of the WEB and the aneurysm dome, confirmed by VasoCT in 2 different views $(G$ and $H)$.

opacification outside the WEB. Finally, in case of opacification in the WEB and at the level of the dome (Fig 5), an additional treatment should be proposed (patient 4). Potential additional treatments have been discussed previously in the literature. ${ }^{24,25}$

\section{Contrast-in-WEB Phenomenon and WEB Shape Modification}

An ancillary finding in this series is that in cases of the contrast-inWEB phenomenon, there is no WEB shape modification. This phenomenon was initially reported by Cognard and Januel ${ }^{15}$ and erroneously named "compression." Pierot ${ }^{26}$ subsequently suggested that this phenomenon was not compression but is part of the healing process, with thrombus formation and retraction leading to retraction of the device itself.

The contrast-in-WEB phenomenon confirms the hypothesis of Pierot ${ }^{26}$ that in case of absence of intra-WEB thrombosis, there is no WEB shape modification.

\section{Limitations}

This series has several limitations. First it is a retrospective, single-center series. Because this study reports a phenomenon that 
was previously unknown, there is no other option than to report it in this way. Second, we have proposed several hypotheses regarding the mechanisms of this phenomenon, yet there is clearly a need for further investigation and studies to understand this phenomenon fully. Finally, we have made several suggestions regarding the management of this phenomenon, but a clearer understanding of the underlying mechanisms will potentially change treatment recommendations.

\section{CONCLUSIONS}

This series reports a rare phenomenon (6.3\%) observed after aneurysm treatment with the WEB that consists of delayed opacification of the WEB $\geq 6$ months after the procedure. Further studies are needed to understand this phenomenon that is potentially related to the use of DAPT postoperatively as well as insufficient coverage of the neck. According to this preliminary series, the phenomenon seems to be associated with a low risk of bleeding, but larger studies with longer follow-up are needed to confirm this point.

Disclosures: Laurent Pierot-RELATED: Consulting Fee or Honorarium: MicroVention; UNRELATED: Consultancy: Balt, phenox, Vesalio.

\section{REFERENCES}

1. Gawlitza M, Soize S, Manceau PF, et al. An update on intrasaccular flow disruption for the treatment of intracranial aneurysms. Expert Rev Med Devices 2019;16:229-36 CrossRef Medline

2. Pierot L, Moret J, Barreau X, et al. Safety and efficacy of aneurysm treatment with WEB in the cumulative population of three prospective, multicenter series. J Neurointerv Surg 2018;10:553-59 CrossRef Medline

3. Arthur AS, Molyneux A, Coon AL, et al; WEB-IT Study Investigators. The safety and effectiveness of the Woven EndoBridge (WEB) system for the treatment of wide-necked bifurcation aneurysms: final 12-month results of the pivotal WEB Intrasaccular Therapy (WEBIT) Study. J Neurointerv Surg 2019;11:924-30 CrossRef Medline

4. Lubicz B, Klisch J, Gauvrit JY, et al. WEB-DL endovascular treatment of wide-neck bifurcation aneurysms: short- and midterm results in a European Study. AJNR Am J Neuroradiol 2014;35:43238 CrossRef Medline

5. Liebig T, Kabbasch C, Strasilla C, et al. Intrasaccular flow disruption in acutely ruptured aneurysms: a multicenter retrospective review of the use of the WEB. AJNR Am J Neuroradiol 2015;36:1721-27 CrossRef Medline

6. van Rooij SB, van Rooij WJ, Peluso JP, et al. WEB treatment of ruptured intracranial aneurysms: a single-center cohort of 100 patients. AJNR Am J Neuroradiol 2017;38:2282-87 CrossRef Medline

7. Klisch J, Sychra V, Strasilla C, et al. The Woven EndoBridge Cerebral Aneurysm Embolization Device (WEB II): initial clinical experience. Neuroradiology 2011;53:599-607 CrossRef Medline

8. Pierot L, Klisch J, Liebig T, et al. WEB-DL endovascular treatment of wide-neck bifurcation aneurysms: long-term results in a European series. AJNR Am J Neuroradiol 2015;36:2314-19 CrossRef Medline

9. Pierot L, Spelle L, Molyneux A, et al; WEBCAST and French Observatory Investigators. Clinical and anatomical follow-up in patients with aneurysms treated with the WEB device: 1-year follow-up report in the cumulated population of 2 prospective, multicenter series (WEBCAST and French Observatory). Neurosurgery 2016;78:133-41 CrossRef Medline

10. Pierot L, Moret J, Turjman F, et al. WEB treatment of intracranial aneurysms: feasibility, complications, and 1-month safety results with the WEB DL and WEB SL/SLS in the French Observatory. AJNR Am J Neuroradiol 2015;36:922-27 CrossRef Medline

11. Pierot L, Moret J, Turjman F, et al. WEB treatment of intracranial aneurysms: clinical and anatomic results in the French Observatory. AJNR Am J Neuroradiol 2016;37:655-59 CrossRef Medline

12. Pierot L, Molyneux A, Byrne J. O-020 WEB ${ }^{\circledR}$ aneurysm treatment: preliminary results of WEBCAST 2 study. J Neurointerv Surg 2016;8 (Suppl 1):A13-14

13. Pierot L, Costalat V, Moret J, et al. Safety and efficacy of aneurysm treatment with WEB: results of the WEBCAST study. J Neurosurg 2016;124:1250-56 CrossRef Medline

14. Pierot L, Gubucz I, Buhk J, et al. Safety and efficacy of aneurysm treatment with the WEB: results of the WEBCAST 2 study. AJNR Am J Neuroradiol 2017;38:1151-55 CrossRef Medline

15. Cognard C, Januel AC. Remnants and recurrences after the use of the WEB intrasaccular device in large-neck bifurcation aneurysms. Neurosurgery 2015;76:522-30 CrossRef Medline

16. Herbreteau D, Bibi R, Narata AP, et al. Are anatomic results influenced by WEB shape modification? Analysis in a prospective, single-center series of 39 patients with aneurysms treated with the WEB. AJNR Am J Neuroradiol 2016;37:2280-86 CrossRef Medline

17. Pierot L, Moret J, Barreau X et al. Aneurysm treatment with Woven EndoBridge in the cumulative population of three prospective, multicenter series: 2-year follow-up. Neurosurgery 2020 Jan 20. [Epub ahead of print] CrossRef Medline

18. Soize S, Gawlitza M, Raoult H, et al. Imaging follow-up of intracranial aneurysms treated by endovascular means. Stroke 2016;47:1407-12 CrossRef Medline

19. Timsit C, Soize S, Benaissa A, et al. Contrast-enhanced and time-offlight MRA at 3T compared with DSA for the follow-up of intracranial aneurysms treated with the WEB device. AJNR Am J Neuroradiol 2016;37:1684-89 CrossRef Medline

20. Nawka MT, Sedlacik J, Frölich A, et al. Multiparametric MRI of intracranial aneurysms treated with the Woven EndoBridge (WEB): a case of Faraday's cage? J Neurointerv Surg 2018;10:988-94 CrossRef Medline

21. Chueh JY, Vedantham S, Wakhloo AK, et al. Aneurysm permeability following coil embolization: packing density and coil distribution. J NeurontervSurg 2015;7:676-81 CrossRef Medline

22. Pierot L, Cognard C, Anxionnat R, et al; for the CLARITY Investigators. Ruptured intracranial aneurysms: factors affecting the rate and outcome of endovascular treatment complications in a series of 782 patients (CLARITY study). Radiology 2010;256:916-23 CrossRef Medline

23. Johnston SC, Dowd CF, Higashida RT, et al; CARAT Investigators. Predictors of rehemorrhage after treatment of ruptured intracranial aneurysms. Stroke 2008;39:120-25 CrossRef Medline

24. Pierot L, Bannery C, Batchinsky-Parrou V, et al. Clipping of recanalized intracerebral aneurysms initially treated by the Woven EndoBridge device. J Neurointerv Surg 2019;11:807-11 CrossRef Medline

25. Durner G, Özpeynirci Y, Schmitz B, et al. Clipping as re-treatment strategy after treatment of a cerebral aneurysm with the Woven EndoBridge embolization device: case report. J Neurosurg 2018 Mar 1. [Epub ahead of print] CrossRef Medline

26. Pierot L. Letter: WEB aneurysm treatment: occlusion stability and “compression.” Neurosurgery 2015;77:E666-67 CrossRef Medline 